\title{
Influence of washing and thermal post-treatment on the adhesion between 3D-printed TPU and woven fabrics
}

\author{
Jannik Störmer, Daniel Görmer, Andrea Ehrmann* \\ Bielefeld University of Applied Sciences, Faculty of Engineering and Mathematics, Bielefeld, Germany \\ ${ }^{*}$ Corresponding author E-mail address: andrea.ehrmann@fh-bielefeld.de
}

\section{INFO}

CDAPT, ISSN 2701-939X

Peer reviewed article

2021, Vol. 2, No. 1, pp. 34-39

DOI 10.25367/cdatp.2021.2.p34-39

Received: 14 May 2021

Accepted: 08 June 2021

Available online: 09 June 2021

\begin{abstract}
$3 D$ printing on textile fabrics can be used to create composites with position-dependent mechanical, water-resistant, magnetic or other properties. An important prerequisite to use such composites technologically or for design purposes is a sufficient adhesion between both materials. While previous studies revealed that soft, elastic printing polymers were advantageous to prepare connections with a high adhesion, not much research has been performed yet on the dependence of the adhesion on textile fabric structure, heat post-treatment, and the influence of washing, which is necessary for most applications of such composites. Here we investigate composites from thermoplastic polyurethane (TPU) 3Dprinted on two different woven cotton fabrics. Besides the expected strong correlation of the adhesion with the distance between nozzle and printing bed, we find a higher adhesion on the thinner fabric and an increase in the adhesion after one washing cycle.
\end{abstract}

(C) 2021 The authors. Published by CDAPT.

This is an open access article under the CC BY-NC-ND license https://creativecommons.org/licenses/ peer-review under responsibility of the scientific committee of the CDAPT.

\section{Introduction}

During the last years, 3D printing has more and more emerged from a rapid prototyping to a rapid printing technology, allowing for producing single objects or complicated shapes which cannot be produced in a different way. One of the problems in the utilization of 3D printing techniques for a broader range of applications is the relatively low mechanical stability due to the layered production process, for which several research groups suggested different possible solutions [1-3].

Besides integrating nano- or microfibers into the filament, thermal post-treatment or inventing new polymers with improved mechanical properties [4-6], combining 3D printed objects with textile fabrics can increase the tensile properties of the 3D print and the stiffness of the fabric, respectively. While recently 
a first proof-of-principle showed that this combination is possible with stereolithography (SLA) [7], most research groups investigate combinations of textile fabrics with 3D printed objects produced by fused deposition modelling (FDM).

In most cases, combining relatively dense fabrics without large pores with rigid 3D printing filaments, such as poly(lactic acid (PLA) or acrylonitrile butadiene styrene (ABS) results in severe problems with the adhesion between both parts of these composites, resulting in a large amount of research dealing with this challenge. Different groups found, e.g., an influence of the printing bed temperature [8], the textile structure [9-12] and especially the distance between nozzle and fabric $[13,14]$ on the adhesion. In addition, chemical pretreatment of the textile fabrics $[15,16]$ or thermal post-treatments $[16,17]$ could alter the adhesion in a positive or also negative way.

Another way to receive a strong adhesion between both parts of the composites is using thermoplastic polyurethane (TPU) or similar elastic printing materials which can more easily penetrate into the fabric and thus build form-locking connections $[17,18]$. In a previous study, we found that a thermal posttreatment by ironing further increased the adhesion forces between TPU and warp-knitted fabrics [17]. Here, we report on printing TPU on two different cotton woven fabrics, partly using a heat press to perform thermal post-treatment under well-defined pressure, and testing the adhesion before and after washing to enable using such sandwiches for clothing applications.

\section{Experimental}

The 3D printer used is a CR-10S Pro (Creality, Shenzhen, China) with a nozzle diameter of $0.4 \mathrm{~mm}$. Rectangles with dimensions of $120 \mathrm{~mm} \times 25 \mathrm{~mm} \times 0.8 \mathrm{~mm}$ were printed with a layer thickness of $0.2 \mathrm{~mm}$ and a printing speed of $15 \mathrm{~mm} / \mathrm{s}$ for all parts of the objects (perimeters, top/bottom layers, infill). The infill density is $100 \%$ with an orientation of $\pm 45^{\circ}$. The reference point for the printing bed leveling, performed by a feeler gauge at 5 positions, is $0.2 \mathrm{~mm}$, i.e. the optimum height for printing directly on the printing bed.

The tests were carried out with the TPU filament Filaflex 82A (Recreus, Elda, Spain) and two different fabrics made of $100 \%$ cotton. Thickness measurements were taken with a caliper gauge and with a textile thickness tester J-40-T (Wolf-Messtechnik GmbH, Freiberg, Germany). While the latter gives the conventional textile thickness, the first value measured a compressed thickness which is more relevant for the situation of 3D printing on the fabric, where the nozzle is also pressed onto the fabric on a small area. One fabric is $0.2 \mathrm{~mm}(0.37 \mathrm{~mm})$ thick and has a firmer fabric structure (plain weave, warp threads $22 / \mathrm{cm}$, weft threads $25 / \mathrm{cm}$ ), the other one is $0.4 \mathrm{~mm}(0.78 \mathrm{~mm})$ thick and has a softer structure (twill $1 / 3$, warp threads $18 / \mathrm{cm}$, weft threads $24 / \mathrm{cm}$ ). The textile fabric was glued onto the printing bed with greentape, slightly stretched so that the nozzle could not move it laterally. The filament was printed at a nozzle temperature of $230{ }^{\circ} \mathrm{C}$. The heatable print bed remained deactivated. Offsets of $-0.05 \mathrm{~mm}$ and $-0.15 \mathrm{~mm}$ with respect to the reference height were used for printing, i.e. printing was performed "inside" the fabrics in all cases, with the distance between nozzle and printing bed being smaller than the textile thickness. Adhesion tests were performed with samples printed with both offsets.

The heat post-treatment was performed by a heat press YF-14 (GuangZhou Amonstar Trade Co.,Ltd, London, United Kingdom). The thermopressing process was carried out for 10 seconds at $180{ }^{\circ} \mathrm{C}$ (thin fabric) and for 10 seconds at $200{ }^{\circ} \mathrm{C}$ (thick fabric), respectively, with constant pressure. The textile fabric was placed on the heated side of the press to prevent the polymer part from being heated too strongly.

Some of the samples with and without thermal post-treatment were washed using a Miele Novotronic W986 WPS (Miele \& Cie. KG, Gütersloh, Germany) and the textile care product "Der Weiße Riese" (Henkel Wasch- und Reinigungsmittel, Düsseldorf, Germany). Cleaning was performed using the "Easy Care $40{ }^{\circ} \mathrm{C}$ " program for 30 minutes, plus a 30-minute spin cycle at $900 \mathrm{rpm}$. For drying, the samples were hung on a clothes rack and air dried. 
The adhesion between textile fabric and imprinted polymer was investigated on a Sauter universal testing machine at a speed of $100 \mathrm{~mm} / \mathrm{min}$. The procedure was based on DIN 53530 (for a sketch of the test, cf. [17]); the tests were evaluated in accordance with ISO 6133. For each sample, one end of the filament was manually detached from the textile and clamped in the Sauter machine to perform the adhesion force test. All tests were performed with 4 replicates.

\section{Results and discussion}

Fig. 1 shows the results of all adhesion tests performed on the raw, unwashed specimens, untreated or after thermal post-treatment.

Firstly, comparing the untreated fabrics, it is obvious that printing at a lower nozzle position, i.e. at $-0.15 \mathrm{~mm}$ (in other words $0.05 \mathrm{~mm}$ above the printing bed), is clearly advantageous for the adhesion. Unexpectedly, the highest values are here not reached for the thick woven fabric, but for the thin one.

Comparing the heat-treated samples, they show mostly an increased adhesion force, with the values of the thin sample printed at $-0.15 \mathrm{~mm}$ being similar to the one of the untreated specimens. The smallest adhesion forces can be found for the thick samples printed at the higher nozzle position of $-0.05 \mathrm{~mm}$.

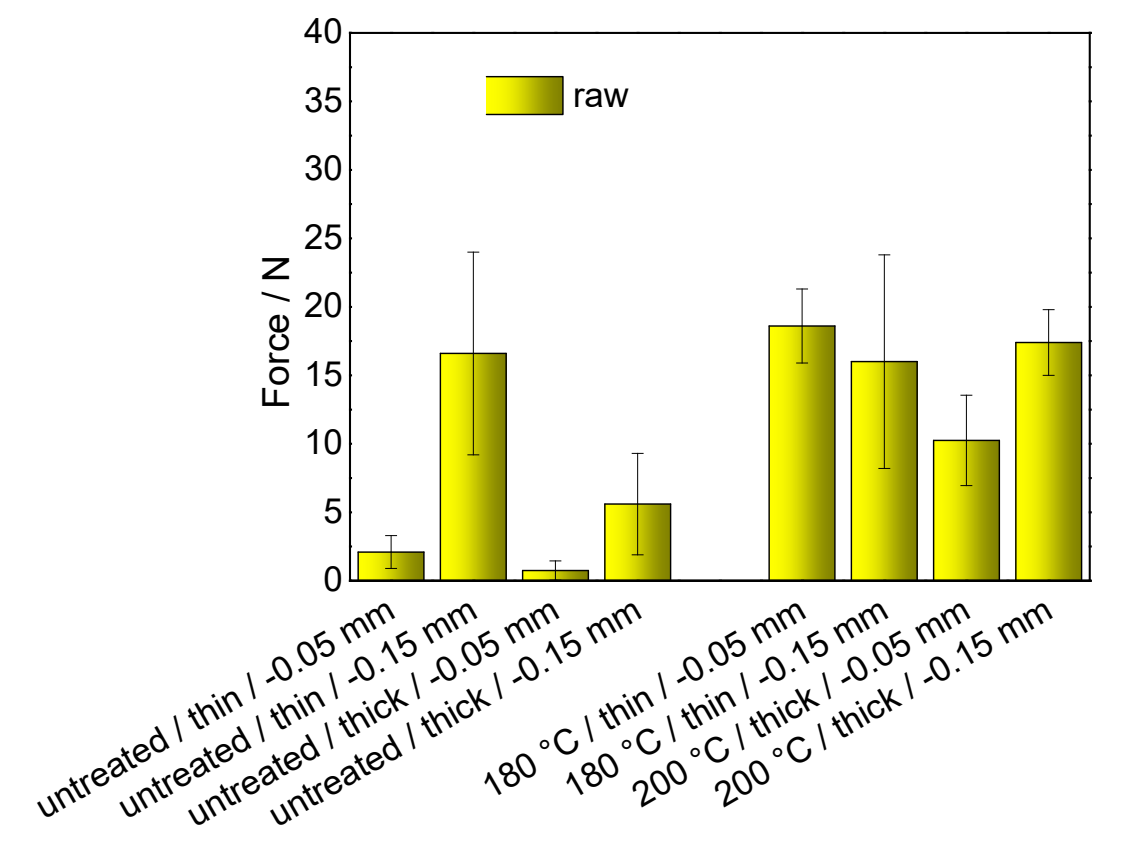

Fig. 1 Results of adhesion tests after printing and partly heat-treating.

To understand this behavior, Fig. 2 shows microscopic images of the untreated samples, comparing the back of the 3D printed parts after the adhesion tests. Interestingly, the TPU layers on the thin fabric (Fig. $2 a, b)$ show stronger imprints of the fabric on which they were printed than the TPU on the thick fabrics (Fig. 2c, d). This finding can be correlated with the thicker fabric being "softer" due to its twill structure which allows for shifting the single threads away during printing, while the plain weave structure of the thin fabric impedes sliding of the yarns. Besides, the imprinted structure seems to have sharper edges for the samples printed at $-0.15 \mathrm{~mm}$, as compared to those printed at the higher nozzle position, which underlines the importance of the distance between nozzle and printing bed.

In both cases, a deeper look at the images reveals more fibers on the TPU layer, thrown out of the respective fabrics during the adhesion tests, for the lower nozzle position of $-0.15 \mathrm{~mm}$. This explains the clear differences between the adhesion forces of the samples printed at higher and lower nozzle position. 

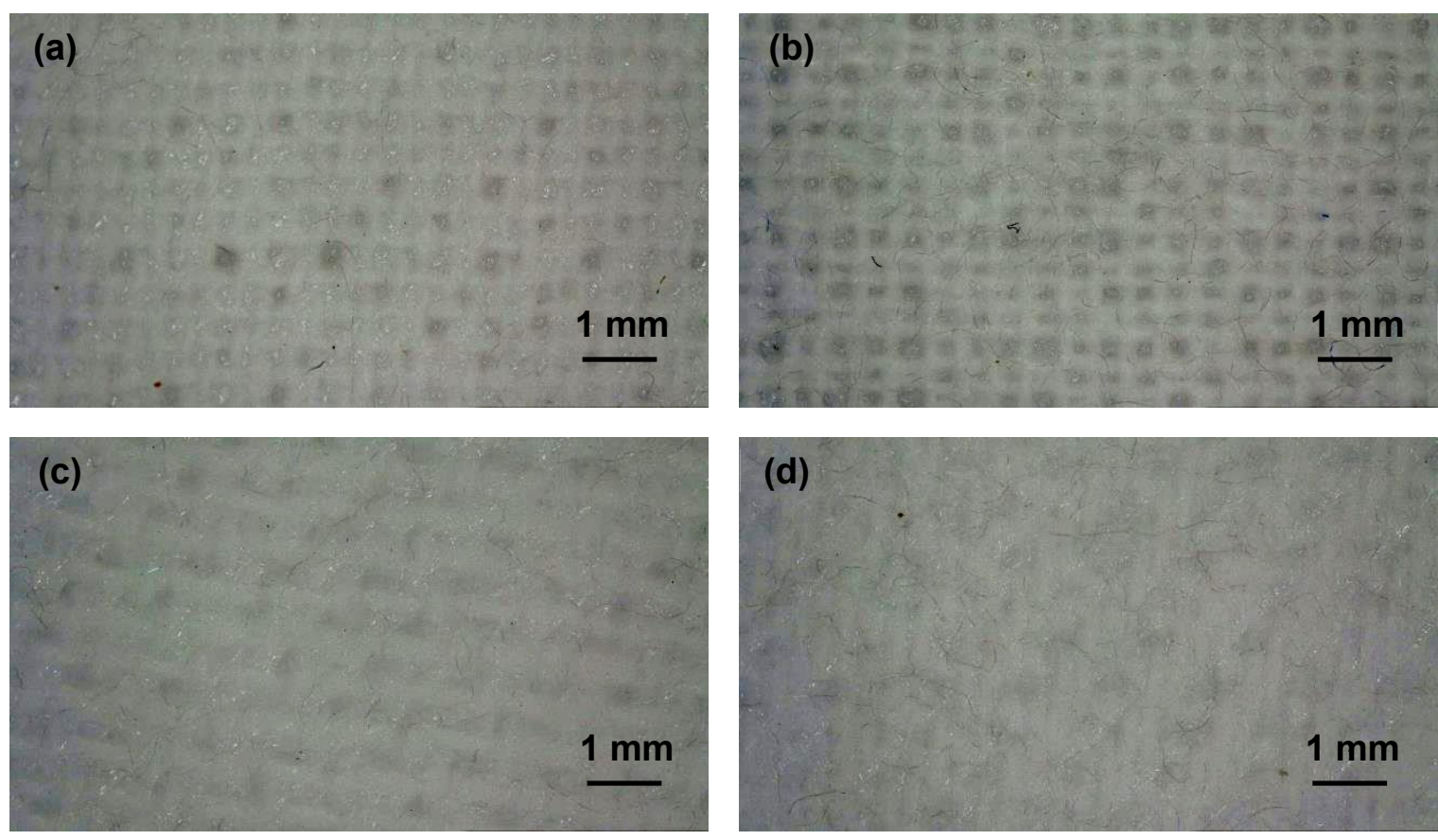

Fig. 2 Microscopic images of the back of the detached TPU after adhesion tests performed on the untreated samples. (a) thin fabric, $-0.05 \mathrm{~mm}$; (b) thin fabric, $-0.15 \mathrm{~mm}$; (c) thick fabric, $-0.05 \mathrm{~mm}$; (d) thick fabric, $-0.15 \mathrm{~mm}$

Comparing the lower side of the TPU parts of the heat-treated specimens, the imprinted structures remain unaltered, while some more fibers detached from the textile fabrics become visible (not shown here). This indicates that although the temperatures used for heat-pressing are sufficient to soften the TPU, the polymer does not melt completely, so that the penetration into the textile fabric cannot be increased. Only the attachment to the upper fibers of the textile fabrics is improved, which is, however, sufficient to increase the adhesion in most cases significantly.

Next, Fig. 3 depicts the results of the adhesion tests after washing the samples. Surprisingly, most values are larger than those measured for the unwashed samples, while the opposite behavior had been expected.

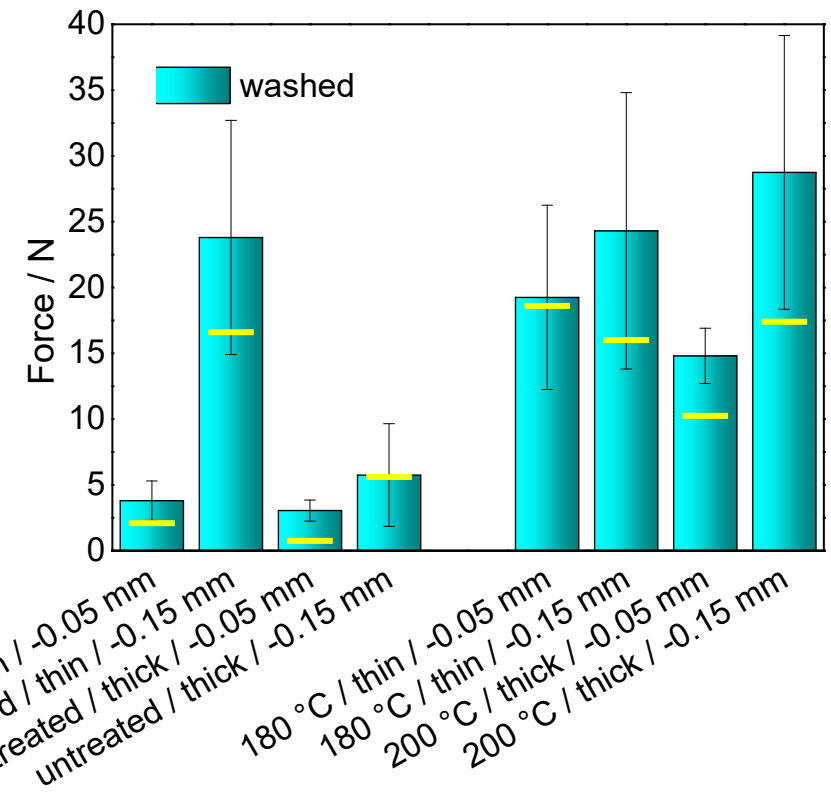

Fig. 3 Results of adhesion tests after washing the printed and partly heat-treated samples. Yellow bars indicate the average values of the raw samples, as shown in Fig. 1 
Comparing the untreated samples, again the thin fabric with the lower nozzle position of $-0.15 \mathrm{~mm}$ shows the highest adhesion. In case of the heat-treated samples, these show again mostly higher adhesion values then the untreated specimens, with a tendency to larger adhesion values for the samples printed at the lower nozzle position of $-0.15 \mathrm{~mm}$. Microscopic images of the back of the TPU parts do not show significant differences from the investigations of the unwashed samples.

These tests indicate that washing does not generally reduce the adhesion between 3D printed TPU parts on textile fabrics. It must be mentioned, however, that the objects used here are thin layers which are less prone to be torn off the fabric than higher object which may be printed on clothing due to design aspects. Besides, here we show the results for a first washing test, while tests with 10 or more washing cycles must follow.

The increase of the adhesion due to washing, found for most of the samples, is not easy to explain and needs further investigations. Washing was performed at $40{ }^{\circ} \mathrm{C}$, i.e. far below the printing temperature, so that no structural modifications of the polymer layer can be expected. Thus, most probably, small changes happened inside the woven fabrics, i.e. relaxation processes as usual due to the combination of temperature, reduced yarn-yarn friction because of water and detergent, and the input of mechanical energy [19]. In this way, the fabric may become slightly denser, thus increasing the form-locking connection to the imprinted polymer layer. At the same time, the single cotton fibers may experience a better adhesion inside the yarn, so that pulling them out of the yarn, as it happens for many fibers during the adhesion test, will become harder. These assumptions, however, have to be investigated further in the future.

Another topic which must be discussed is the length of the error bars in Figs. 1 and 3. In most cases, the standard deviations are relatively large. This can be attributed to slightly varying distances between nozzle and printing bed, either due to an uneven printing bed or due to small deviations stemming from the (manual) adjustment of the printing bed.

While many printers nowadays offer the possibility to level the printing bed automatically directly before printing, this procedure is not possible if a textile fabric is already glued onto the printing bed. On the other hand, comparing the adhesion of the untreated fabrics, it is obvious that a height error of $0.1 \mathrm{~mm}$ already causes significant deviations of the adhesion (cf. Figs. 1 and 3). This suggests developing a procedure which enables auto-levelling in spite of textile fabrics being glued on the printing bed; a topic at which a recent study of our group is aiming.

\section{Conclusions}

Cotton fabrics of different thickness and woven structure were 3D-imprinted with TPU to test the adhesion between both partners of this composite. Unexpectedly, the adhesion of the untreated fabrics was higher on the thin plain weave fabric than on the thick twill fabric. On the other hand, the expected influence of the distance between nozzle and printing bed was verified. After heat-pressing the samples, these differences were largely leveled out. Washing the samples unexpectedly increased the adhesion slightly.

As the large deviations of the adhesion within one specimen or between nominally identical specimens, printed on neighboring positions of the printing bed, show, it is necessary to define a process to allow for auto-levelling the printing bed for the case of a textile fabric glued onto the printing bed.

\section{References}

[1] Arunothayan, A. R.; Nematollahi, B.; Ranade, R.; Bong, S. H.; Sanjayan, J. Development of 3D-printable ultrahigh performance fiber-reinforced concrete for digital construction. Construction and Building Materials 2020 , 257, 119546. DOI 10.1016/j.conbuildmat.2020.119546.

[2] Afshar, A.; Mihut, D. Enhancing durability of 3D printed polymer structures by metallization. J. Mater. Sci. Technol. 2020, 53, 185-191. DOI 10.1016/j.jmst.2020.01.072. 
[3] Oviedo, A. M.; Puente, A.H.; Bernal, C.; Perez, E. Mechanical evaluation of polymeric filaments and their corresponding 3D printed samples. Polymer Testing 2020, 88, 106561. DOI 10.1016/j.polymertesting.2020.106561.

[4] Dong, J.; Mei, C. T.; Han, J. Q.; Lee, S. Y.; Wu, Q. L. 3D printed poly(lactic acid) composites with grafted cellulose nanofibers: Effect of nanofiber and post-fabrication annealing treatment on composite flexural properties. Additive Manufacturing 2019, 28, 621-628. DOI 10.1016/j.addma.2019.06.004.

[5] Chalgham, A.; Wickenkamp, I.; Ehrmann, A. Mechanical properties of FDM printed PLA parts before and after thermal treatment. Polymers 2021, 13, 1239. DOI: 10.3390/polym13081239.

[6] Stepashkin, A. A.; Chukowv, D. I.; Senatov, F. S.; Salimon, A. I.; Korsunsky, A. M. Kaloshkin, S. D. 3D-printed PEEK-carbon fiber (CF) composites: structure and thermal properties. Composites Science and Technology 2018, 164, 319-326. DOI: 10.1016/j.compscitech.2018.05.032.

[7] Grothe, T.; Brockhagen, B.; Storck, J. L. Three-dimensional printing resin on different textile substrates using stereolithography: A proof of concept. J. Eng. Fibers Fabrics 2020, 1, 1558925020933440. DOI: 10.1177/1558925020933440.

[8] Eutionnat-Diffo, P. A.; Chen, Y.; Guan, J. P.; Cayla, A.; Campagne, C.; Zeng, X. Y.; Nierstraz, V. Stress, strain and deformation of poly-lactic acid filament deposited onto polyethylene terephthalate woven fabric through 3D printing process. Sci. Rep. 2019, 9, 14333. DOI 10.1038/s41598-019-50832-7.

[9] Narula, A.; Pastore, C.; Schmelzeisen, D.; El Basri, S.; Schenk, J.; Shajoo, S. Effect of knit and print parameters on peel strength of hybrid 3D printed textiles. J. Text. Fibrous Mater. 2018, 1: 2515221117749251. DOI 10.1177/2515221117749251.

[10] Meyer, P.; Döpke, C.; Ehrmann, A. Improving adhesion of three-dimensional printed objects on textile fabrics by polymer coating. J. Eng. Fibers Fabrics 2019, 14, 1558925019895257. DOI 10.1177/1558925019895257.

[11] Calvo, J.O.; Martin, A.C.; Ferradas, M.I.R.; Morcillo, P.L.F.; Munoz, L.M.; Camo, P.M. Additive manufacturing on textiles with low-cost extrusion devices: Adhesion and deformation properties. Dyna 2019, 64, 8893. DOI 10.6036/8893.

[12] Mpofu, N. S.; Mwasiagi, J. I.; Nkiwane, L. C.; Njuguna, D. Use of regression to study the effect of fabric parameters on the adhesion of 3D printed PLA polymer onto woven fabrics. Fashion and Textiles 2019, 6, 24. DOI 10.1186/s40691-019-0180-6.

[13] Grimmelsmann, N.; Kreuziger, M.; Korger, M.; Meissner, H.; Ehrmann, A. Adhesion of 3D printed material on textile substrates. Rapid Prototyping J. 2018, 24(1), 166-170. DOI 10.1108/RPJ-05-2016-0086.

[14] Spahiu, T.; Al-Arabiyat, M.; Martens, Y.; Ehrmann, A.; Piperi, E.; Shehi, E. Adhesion of 3D printing polymers on textile fabrics for garment production. IOP Conf. Ser.: Mater. Sci. Eng. 2018, 459, 012065. DOI: 10.1088/1757-899X/459/1/012065.

[15] Korger, M.; Bergschneider, J.; Lutz, M.; Mahltig, B.; Finsterbusch, K.; Rabe, M. Possible Applications of 3D Printing Technology on Textile Substrates. IOP Conf. Ser.: Mater. Sci. Eng. 2016, 141, 012011. DOI 10.1088/1757-899X/141/1/012011.

[16] Kozior, T.; Döpke, C.; Grimmelsmann, N.; Juhász Junger, I.; Ehrmann, A. Influence of fabric pretreatment on adhesion of three-dimensional printed material on textile substrates. Adv. Mech. Eng. 2018, 10, 792316. DOI 10.1177/1687814018792316.

[17] Görmer, D.; Störmer, J.; Ehrmann, A. The influence of thermal after-treatment on the adhesion of 3D prints on textile fabrics. Communications in Development and Assembling of Textile Products 2020, 1, 104-110.

[18] Korger, M.; Glogowsky, A.; Sanduloff, S.; Steinem, C.; Huysman, S.; Horn, B.; Ernst, M.; Rabe, M. Testing thermoplastic elastomers selected as flexible three-dimensional printing materials for functional garment and technical textile applications. J. Eng. Fibers Fabrics 2020, 15, 1558925020924599. DOI 10.1177/1558925020924599.

[19] Ehrmann, A.; Heimlich, F.; Brücken, A.; Weber, M.O.; Blachowicz, T. Experimental investigation of the washing relaxation of knitted fabrics from polyester yarn with stainless steel fibers. Fibres \& Textiles in Eastern Europe 2012, 20, 90-93. 